\title{
Effect of the substituents on the nature and strength of lone pair-carbonyl interactions in acyl halides
}

\author{
Juan D. Velásquez ${ }^{\mathrm{a}}$, Jorge Echeverría*a and Santiago Alvarez ${ }^{\mathrm{a}}$ \\ aDepartament de Química Inorgànica i Orgànica and Institut de Química Teòrica i \\ Computacional (IQTC-UB), Universitat de Barcelona, Martí i Franquès 1-11, \\ 08028 Barcelona (Spain). E-mail: jorge.echeverria@qi.ub.es
}

\begin{abstract}
We have performed a combined structural and theoretical analysis of lone paircarbonyl interactions in several families of acyl halides (R-CO-X). CSD searches have allowed us to establish the geometrical preferences for such short contacts. The study of the molecular electrostatic potential (MEP) of several molecules along with energy decomposition analyses (EDA) disclosed the nature of the interaction and the factors that affect its strength. To further understand lone pair-carbonyl contacts we have systematically analysed, by means of DFT calculations, the effect of the lone pair as well as of the halogen atom (X) and the substituent attached to the carbonyl group (R). Interaction energies up to 8 $\mathrm{kcal} / \mathrm{mol}$ suggest that these interactions can be exploited in crystal design and supramolecular chemistry.
\end{abstract}




\section{Introduction}

Among the abundance of noncovalent interactions, those involving carbonyl groups have attracted increasing interest in recent years. Short contacts between an electron density donor and the electron-deficient region of a carbonyl group (i.e. the $\mathrm{C}$ atom) have been found and investigated in many families of compounds. ${ }^{1-12}$ The nature of such interactions has been the subject of discussion for a long time.13, 14 It seems clear nowadays that lone paircarbonyl interactions imply the combination of orbital and electrostatic contributions. The orbital interaction is associated with electron density delocalization from the lone pair into the $\pi^{*}$ empty orbital of the carbonyl to establish the so-called $n \rightarrow \pi^{*}$ interaction. ${ }^{15}$ On the other hand, the electrostatic interaction is the result of the attraction between a region of the electron-rich species (the lone pair) and another of the electron deficient one (the carbonyl carbon atom), negatively and positively charged, respectively. ${ }^{16,}{ }^{17}$ This electrostatic interaction has been rationalized in terms of $\pi$-hole bonding by Politzer et al. ${ }^{18}$

From a topological point of view, it is difficult to asses the contribution of each component, orbital and electrostatic, to the total interaction energy since both the $\pi$-hole and the empty $\pi^{*}$ orbital are located in the same molecular region, i.e. the carbon atom of the carbonyl group. The intermolecular distance gives an indication to determine the strength of the $\mathrm{n} \rightarrow \pi^{*}$ interaction, which depends on the $n / \pi^{*}$ orbital overlap. On the other hand, the $\pi$-hole bonding is associated with a marked directionality to precisely connect the positive and negative regions.

Here, we present a combined structural and computational study of lone pair-carbonyl interactions in acyl halides. We want to investigate how the presence of the halogen atom affects the reactivity of the carbonyl groups towards nucleophiles. Furthermore, different substituents on the CO-X groups have been studied as well as oxygen and nitrogen-containing lone pairs. Special attention has been paid to possible correlations between geometrical descriptors and molecular properties, such as the value of the electrostatic potential. To 
further investigate the nature of the interaction, an energy decomposition analysis (EDA) ${ }^{19}$ has been performed on dimers at several interaction distances. Moreover, we have tried to link our theoretical results with experimental structures when possible.

\section{Structural analysis}

We have searched the Cambridge Structural Database (CSD) ${ }^{20}$ for short intermolecular contacts between carbonyl groups of acyl halides and lone paircontaining donor atoms (see Scheme 1). In our searches, the donor (Y) was set to be any element of groups 15, 16 and 17 whereas X could be any halogen. Only contacts shorter than the sum of the van der Waals radii plus $0.1 \AA$ ( $\mathrm{d}_{\mathrm{Y} \cdots \mathrm{C}}<\left(\Sigma r_{\mathrm{vdw}}\right.$ + 0.1)) were taken into account. A total of 111 short $Y \cdots C=0$ contacts were found in 78 different crystal structures for $\mathrm{Y}=\mathrm{N}$ (7 hits), $\mathrm{O}$ (47 hits), F (7 hits) and $\mathrm{Cl}$ (17 hits). As for the nature of the halogen atom X, we found 23 contacts for F, 54 for $\mathrm{Cl}$ and only one for $\mathrm{Br}$.

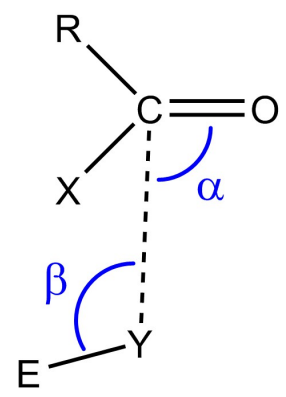

Scheme 1. Angles involved in the interaction between a lone pair-containing group and an acyl halide.

We have then analysed the Y $\cdots \mathrm{C}=0$ attack angle $(\alpha)$ associated with the short Y...C contacts. Remarkably, as the Y..C distance decreases the angle $\alpha$ approaches $100^{\circ}$, as shown in Figure 1. This tendency has been seen before in other lone pair-carbonyl interactions ${ }^{1-3,15}$ and is associated with the BurgiDunitz trajectory for a nucleophilic attack. ${ }^{21,22}$ It can also be seen in the plot of Figure 1 that the shortest contacts are found for $Y=0$, with no contacts below a normalized distance of $-0.2 \AA$ for $\mathrm{Y}=\mathrm{N}, \mathrm{F}$ and $\mathrm{Cl}$ (we define the normalized distance as the difference between the measured experimental distance and the sum of the van der Waals radii of the atoms involved). The outlayer point 
showing a $\mathrm{Cl} \cdots \mathrm{C}$ contact at $-0.3 \AA$ is actually a $\mathrm{Cl} \cdot \cdot \mathrm{O}=\mathrm{C}$ halogen bond with the $\mathrm{Cl} \cdots 0$ distance shorter than the $\mathrm{Cl} \cdots \mathrm{C}$ one (3.009 and 3.281 $\AA$, respectively).

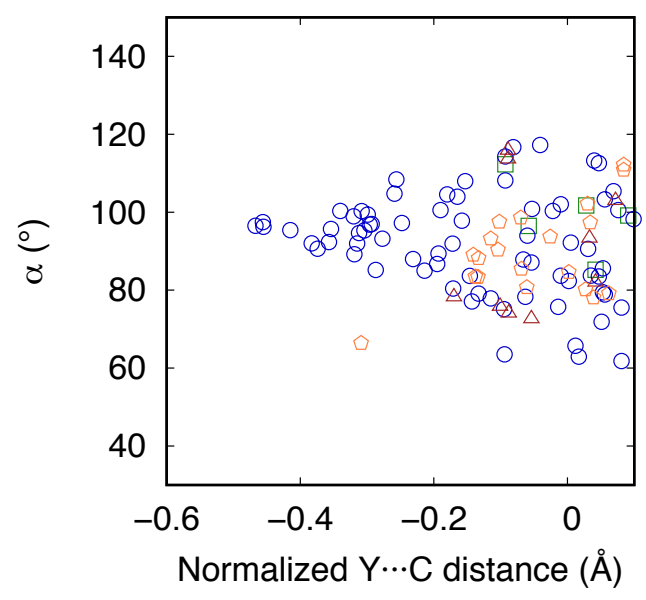

Figure 1. $\mathrm{Y} \cdots \mathrm{C}=\mathrm{O}$ angle as a function of the normalized $\mathrm{Y} \cdots \mathrm{C}$ distance (norm. distance $\left.=\mathrm{d}_{\mathrm{Y} \cdots \mathrm{C}}-\Sigma r_{\mathrm{Vdw}}\right)$. Different donor atoms are represented with different colours: $\mathrm{Y}=\mathrm{N}$ (green squares), $\mathrm{O}$ (blue circles), $\mathrm{F}$ (red triangles) and $\mathrm{Cl}$ (orange pentagons).

The other angle involved in the interaction moiety ( $\beta$, see Scheme 1$)$ also shows some particularities. When the donor atom is a halogen $(\mathrm{Y}=\mathrm{F}, \mathrm{Cl})$ the $78 \%$ of the E-Y $\cdots \mathrm{C}$ angles are located in the range $90-120^{\circ}$ (58\% in $90-100^{\circ}$ ), presumably to facilitate a hypothetical electrostatic interaction dictated by the particular electron density distribution of covalently bonded halogen atoms. On the other hand, when the donor is an $\mathrm{O}$ atom in the form of a carbonyl group the approach angle $\mathrm{C}=0 \cdots \mathrm{C}$ is more variable with a random distribution of values between 80 and $180^{\circ}$, in good agreement with previous reports on carbonylcarbonyl interactions. ${ }^{13}$

We show in Figure 2 an example of crystal structure in which the molecules of fluoroformic acid anhydride (DALJAC) ${ }^{23}$ are held together by carbonyl $\cdots$ carbonyl contacts as the only intermolecular interaction. In such a crystal structure, we found $0 \cdots C$ contacts as short as $2.81 \AA$, i.e. $0.4 \AA$ shorter than the sum of the van der Waals radii. However, the shortest $\mathrm{C}=0 \cdots \mathrm{C}=0$ contact is found at $2.803 \AA\left(\alpha=96.5^{\circ}\right)$ in the crystal structure of pentafluoropropanoyl fluoride (HALWUP), ${ }^{24}$ in which there is also a F... C $=0$ contact at $3.129 \AA$, i.e. $0.1 \AA$ 
shorter than the sum of the corresponding van der Waals radii. In the crystal structure of FAYNOI, in which the donor oxygen is an ether, the $0 \cdots \mathrm{C}$ contact is found at a very short distance of $2.590 \AA$.

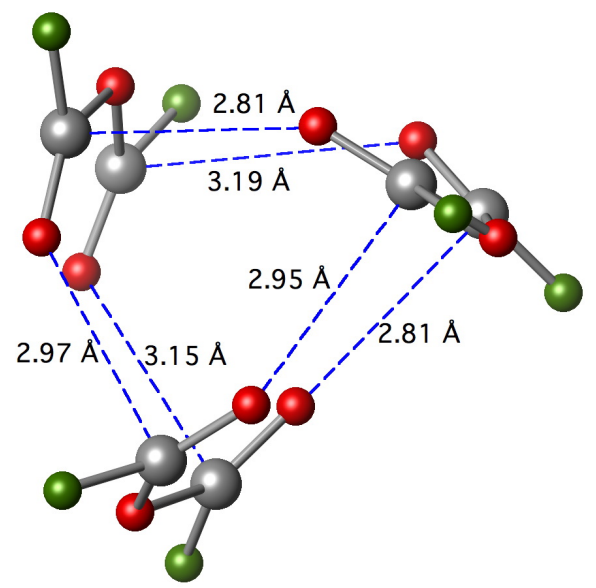

Figure 2. Short carbonyl-carbonyl contacts in the crystal structure of fluoroformic acid anhydride (DALJAC). ${ }^{23}$ Color code: Grey $=\mathrm{C}$, red $=0$ and green $=\mathrm{F}$.

\section{Molecular electrostatic potential (MEP) analysis}

The MEP represented on a van der Waals isosurface is a very useful tool to predict the reactivity of a molecule towards nucleophiles and/or electrophiles. ${ }^{18,25}$ Regions with depletion of the electron density are associated with positive values of the MEP and are prone to interact with lone pairs, anions, or, in general, any electron-rich species. On the other hand, regions with concentration of the electron density, with negative MEP values, will tend to be attracted to electron-deficient species. Although it reduces the interaction to electrostatic forces, the study of the MEP works usually well to explain the reactivity of molecules with $\sigma$ or $\pi$-holes.

Here, we use this approach to analyse a possible electrostatic interaction between acyl halides and lone pairs. Acyl halides of formula $\mathrm{CF}_{3}-\mathrm{COX}(\mathrm{X}=\mathrm{F}, \mathrm{Cl}$, $\mathrm{Br}$ and I) have been first selected to evaluate the effect of the different halogens on the magnitude of the $\pi$-hole associated to the carbonyl carbon atom. The corresponding MEP maps are plotted in Figure 3. As can be seen there, the $\pi$ hole is more pronounced for $\mathrm{X}=\mathrm{F}$ although it is present in all four cases. Values 
of MEP between 46 and $56 \mathrm{kcal} / \mathrm{mol}$ are high enough to expect a marked affinity for electron density donors.

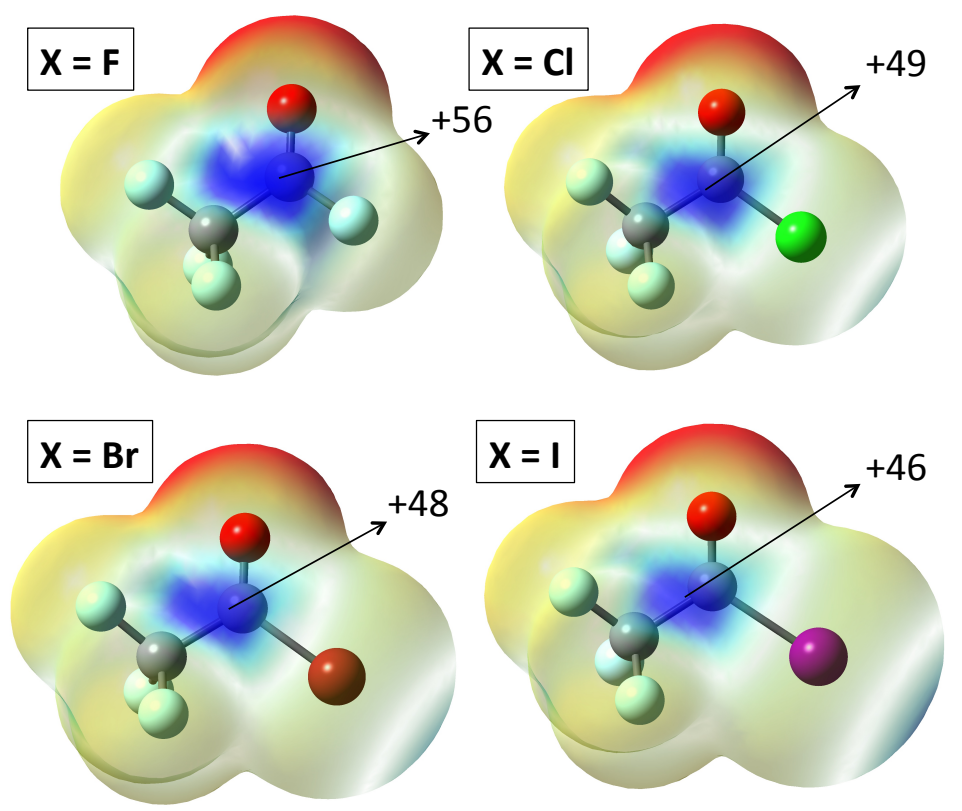

Figure 3. MEP maps for perfluoromethyl fluoroformate derivatives $\mathrm{CF}_{3}-\mathrm{COX}(\mathrm{X}=$ $\mathrm{F}, \mathrm{Cl}, \mathrm{Br}$ and I). Red indicates more negative and blue more positive EP values. Energies are given in $\mathrm{kcal} / \mathrm{mol}$.

Next, we modify the group attached to the fluoroformate moiety (we keep $\mathrm{F}$ as the reference $\mathrm{X}$ because it showed the most marked $\pi$-hole) to study their effect on the electron density distribution over the molecules. Several substituents have been studied $\left(\mathrm{R}=-\mathrm{CH}_{3},-\mathrm{OCH}_{3},-\mathrm{OCF}_{3},-\mathrm{SCN},-\mathrm{NH}_{2},-\mathrm{C}_{6} \mathrm{H}_{5},-\mathrm{C}_{6} \mathrm{H}_{5} \mathrm{~F}\right.$, $-\mathrm{C}_{6} \mathrm{H}_{2} \mathrm{~F}_{3}$ ), all of them realistic since they were found in our structural analysis. The results are presented in Figure 4. Two main groups can be distinguished: those in which the region of maximum MEP value $\left(V_{s, \max }\right)$ is located on the carbonyl carbon atom and those in which $V_{\mathrm{s} \text {, max }}$ is located at other part of the molecule. In the first group we find $\mathrm{R}=-\mathrm{OCH}_{3},-\mathrm{OCF}_{3},-\mathrm{SCN}$ and in the second $\mathrm{R}=$ $-\mathrm{CH}_{3},-\mathrm{NH}_{2},-\mathrm{C}_{6} \mathrm{H}_{5},-\mathrm{C}_{6} \mathrm{H}_{5} \mathrm{~F},-\mathrm{C}_{6} \mathrm{H}_{2} \mathrm{~F}_{3}$. Of course, $\mathrm{R}=-\mathrm{CF}_{3}$, as previously seen (Figure 3 ) is the paradigmatic case of the first group.

The most positive MEP values are found in $\mathrm{R}=-\mathrm{CF}_{3},-\mathrm{OCF}_{3}$ and $-\mathrm{SCN}(56$, 49 and $46 \mathrm{kcal} / \mathrm{mol}$, respectively). For the latter, the presence of the $\mathrm{S}$ atom allows the formation of two clear $\sigma$-holes (38 and $44 \mathrm{kcal} / \mathrm{mol}$ ). As expected, 
when $\mathrm{R}$ is a phenyl ring, the presence of more $\mathrm{F}$ atoms reinforces the $\pi$-hole on the carbonyl. It is expected, thus, that molecules in the first group can interact with electron donors via the carbonyl carbon whereas the others might find more suitable regions and, thus, establish other types of interactions.

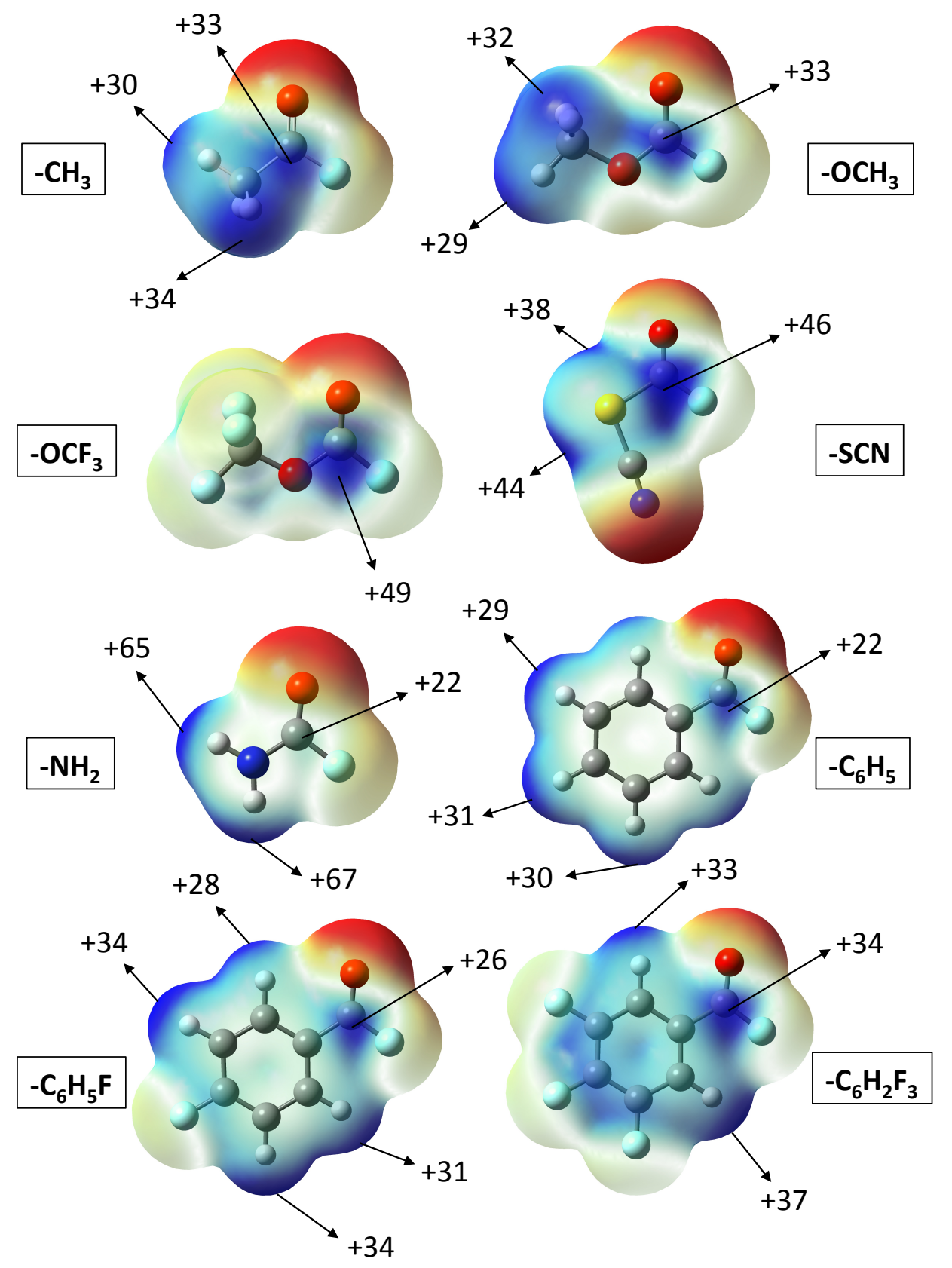




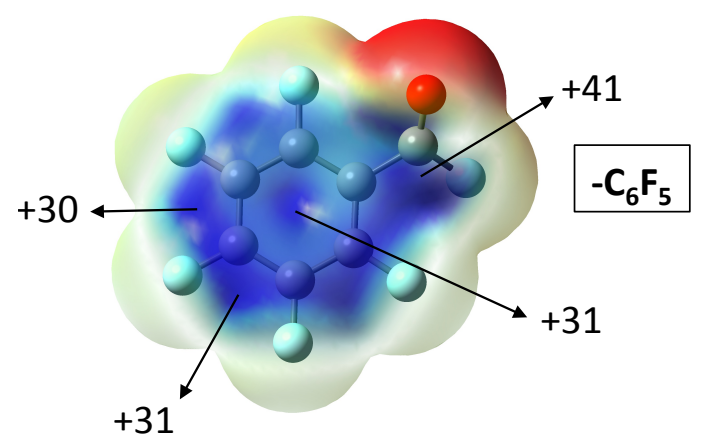

Figure 4. MEP maps for fluoroformate derivatives R-COF $\left(\mathrm{R}=-\mathrm{CH}_{3},-\mathrm{OCH}_{3},-\mathrm{OCF}_{3}\right.$, $-\mathrm{SCN},-\mathrm{NH}_{2},-\mathrm{C}_{6} \mathrm{H}_{5},-\mathrm{C}_{6} \mathrm{H}_{5} \mathrm{~F},-\mathrm{C}_{6} \mathrm{H}_{2} \mathrm{~F}_{3}$ ). Red indicates more negative and blue more positive EP values. Energies are given in $\mathrm{kcal} / \mathrm{mol}$.

\section{Interaction energies}

\section{The effect of $X$}

We have studied, by means of DFT calculations (see Theoretical Methods for further details), the effect of the nature of the halogen $\mathrm{X}$ on the capability of the attached carbonyl group to act as an electron density acceptor. To that end, a model based on the dimer found in the crystal structure of perfluoromethyl chloroformate (ISADOV) ${ }^{26}$ has been used (Figure 5). The absence of hydrogen atoms in this structure avoids the formation of H-bonds that could compete with the $\mathrm{Y} \cdots \mathrm{C}=\mathrm{O}$ interaction. The main results are summarized in Table 1. Interestingly, the intermolecular $0 \cdots \mathrm{C}$ distance increases when going from $\mathrm{F}$ to I. Such trend is not followed by the interaction energy, which shows a nice linear correlation with the $0 \cdots \mathrm{C}=0$ angle $\alpha\left(\mathrm{R}^{2}=0.987\right)$. Large $\alpha$ angles, closer to the Burgi-Dunitz trajectory that maximizes the donor-acceptor orbital overlap, are associated with higher interaction energies. It is worth noting that in all dimers in Table 1 , there is also a $\mathrm{C}=0 \cdots \mathrm{F}-\mathrm{CF}_{2}$ contact at a distance shorter than the sum of the van der Waals radii (but still longer than the main $0 \cdots \mathrm{C}$ contact). For comparison, we have calculated an interaction energy of $3.39 \mathrm{kcal} / \mathrm{mol}$ for the dimer of $\left(\mathrm{CF}_{3}\right)_{2} \mathrm{C}=0\left(\mathrm{~d}_{0} \ldots \mathrm{C}=2.852 \AA ; \alpha=90.30^{\circ}\right)$. 


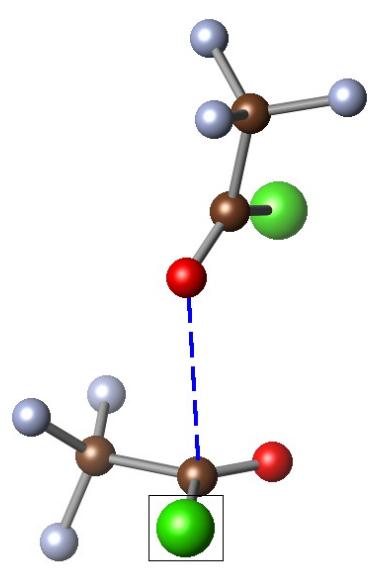

Figure 5. Dimer of perfluoromethyl chloroformate used to analyse the effect of the halide in the acceptor molecule. The framed $\mathrm{Cl}$ atom was substituted by $\mathrm{F}, \mathrm{Br}$ and I. Color code: Brown $=\mathrm{C}$, red $=0$, green $=\mathrm{Cl}$ and purple $=\mathrm{F}$

Table 1. Key geometrical parameters and interaction energies for the optimized dimers of perfluoromethyl haloformate $\left(\mathrm{CF}_{3}-\mathrm{COX} ; \mathrm{X}=\mathrm{F}, \mathrm{Cl}, \mathrm{Br}\right.$ and I).

\begin{tabular}{llll}
\hline $\mathrm{X}$ & $\mathrm{d}_{0 \ldots \mathrm{C}}(\AA)$ & $\alpha\left(^{\circ}\right)$ & $\Delta \mathrm{E}_{\text {int }}(\mathrm{kcal} / \mathrm{mol})$ \\
\hline $\mathrm{F}$ & 2.735 & 95.78 & -3.56 \\
$\mathrm{Cl}$ & 2.801 & 91.67 & -3.13 \\
$\mathrm{Br}$ & 2.830 & 90.12 & -3.03 \\
$\mathrm{I}$ & 2.843 & 90.30 & -3.07 \\
\hline
\end{tabular}

\section{The effect of $R$}

The same approach has been applied to analyse the effect of varying the substituent R. We have used the same R groups as in our previous MEP analysis to try to find a relationship between interaction geometries and molecular electron density holes. Remarkably, the cases in which the $V_{\mathrm{s}, \max }$ is on the carbonyl carbon atom $\left(-\mathrm{OCH}_{3},-\mathrm{OCF}_{3}\right.$ and $\left.-\mathrm{SCN}\right)$ present carbonyl-carbonyl interactions as represented in Figure 6. The $0 \cdots \mathrm{C}$ distances are in the range 2.72$2.82 \AA$ and the interaction energies between -2.80 and $-4.91 \mathrm{kcal} / \mathrm{mol}$. For $\mathrm{R}=$ - 
$\mathrm{OCH}_{3}$, the stronger interaction is explained by the formation of a reciprocal carbonyl-carbonyl interaction ${ }^{27}$ and an additional $\mathrm{C}=0 \cdots \mathrm{H}$ hydrogen bond $(2.554$ $\AA)$. As for the other cases $\left(\mathrm{R}=-\mathrm{CH}_{3},-\mathrm{NH}_{2},-\mathrm{C}_{6} \mathrm{H}_{5},-\mathrm{C}_{6} \mathrm{H}_{5} \mathrm{~F}\right.$ and $\left.-\mathrm{C}_{6} \mathrm{H}_{2} \mathrm{~F}_{3}\right)$, the interaction is reversed, i.e. the $\mathrm{C}=\mathrm{O}$ in $\mathrm{R}-\mathrm{COF}$ acts as the electron density donor while the $\mathrm{C}=\mathrm{O}$ in $\mathrm{CF}_{3}-\mathrm{COF}$ is the acceptor (Figure 6). This can also be explained in terms of MEP distributions by looking at maps in Figure 4 since, in such systems, the $V_{\mathrm{s}, \max }$ is no longer located over the carbonyl of R-COF.
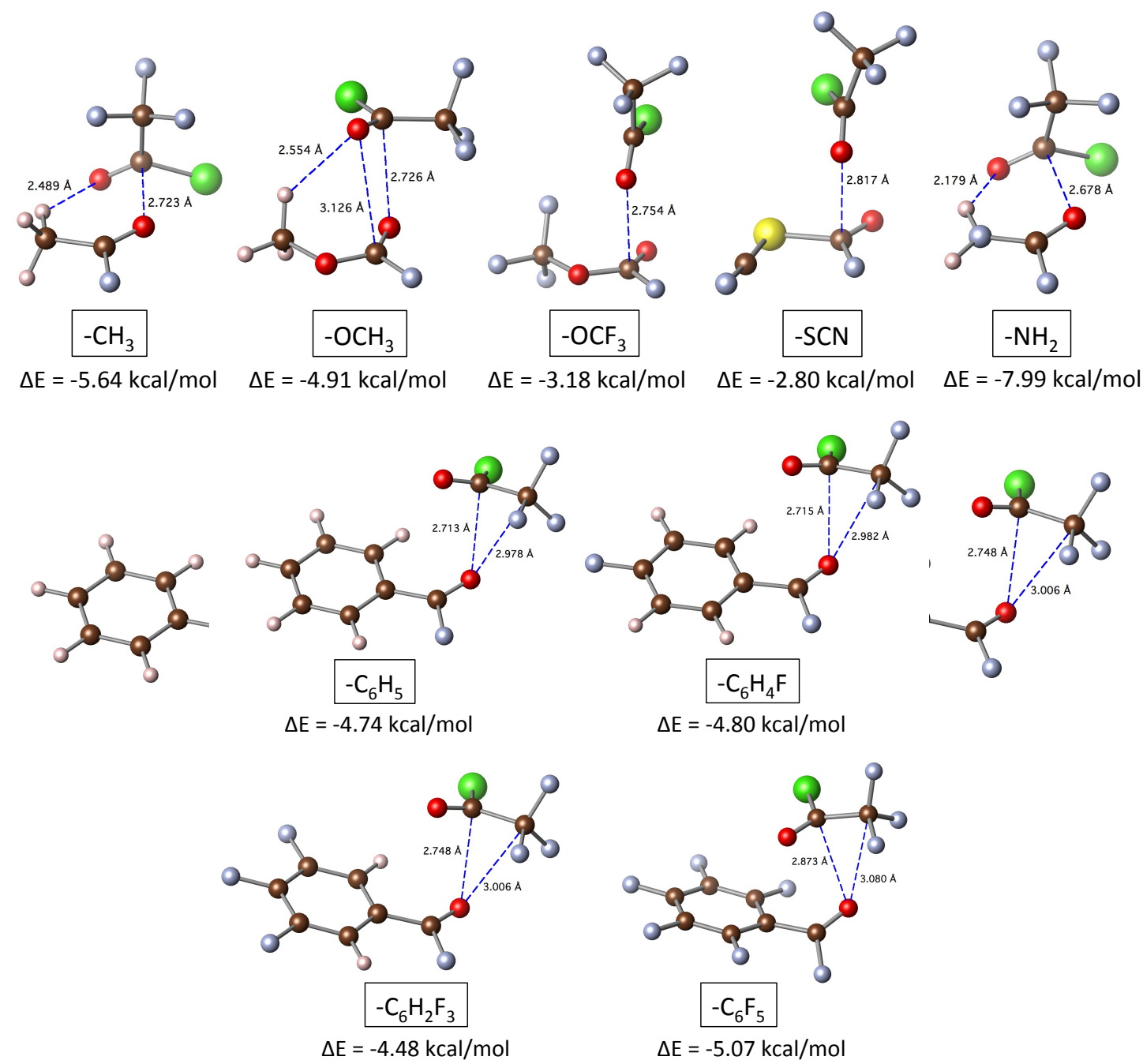

Figure 6. Optimized geometries and interaction energies for the adducts formed by $\mathrm{CF}_{3} \mathrm{COCl}$ as the donor and several fluoroformate derivatives $\left(\mathrm{R}-\mathrm{COF} ; \mathrm{R}=-\mathrm{CH}_{3}\right.$, $\left.-\mathrm{OCH}_{3},-\mathrm{OCF}_{3},-\mathrm{SCN},-\mathrm{NH}_{2},-\mathrm{C}_{6} \mathrm{H}_{5},-\mathrm{C}_{6} \mathrm{H}_{5} \mathrm{~F},-\mathrm{C}_{6} \mathrm{H}_{2} \mathrm{~F}_{3}\right)$ as the acceptors.

The case in which $\mathrm{R}$ is an aromatic ring deserves some closer attention. The interaction pattern between $\mathrm{Ph}-\mathrm{COF}$ and $\mathrm{CF}_{3}-\mathrm{COCl}$ can be described by 
means of three intermolecular distances (Scheme 2). While $d_{1}$ and $d_{2}$ correspond to a reciprocal carbonyl-carbonyl interaction, $\mathrm{d}_{3}$ is a short contact associated to a $\sigma$-hole interaction where the $\mathrm{CF}_{3}$ substituent acts as the acceptor. Remarkably, the topology of the supramolecular aggregate is the result of a delicate balance of those three distances. As we increase the number of fluorine atoms in the ring, $d_{1}$ shortens whereas $d_{2}$ and $d_{3}$ lengthen. It is worth noting that a nice linear correlation is found between the MEP value at the Ph-COF carbonyl and $d_{1}\left(R^{2}=\right.$ 0.989). We have not found, however, any clear trend involving the interaction energy and the studied geometrical parameters.

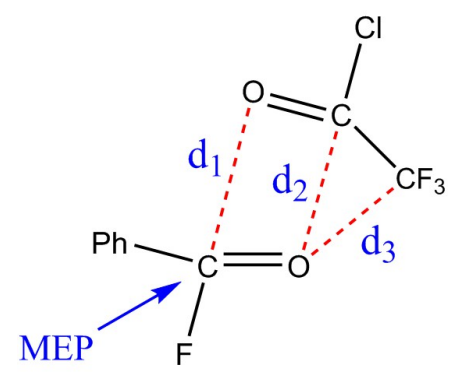

Scheme 2. Intermolecular contacts in the adduct formed by $\mathrm{CF}_{3}-\mathrm{COCl}$ and $\mathrm{Ph}$ COF.

\section{The effect of $Y$}

We have seen that donor molecules with oxygen atoms are able, in some circumstances, to establish hydrogen bonds that compete with the lone paircarbonyl interactions. To avoid this, we have used $\mathrm{N}_{2}$ as the donor molecule and re-optimized all systems of Figure 6. In a recent report, such molecule was successfully used as Lewis base to assess the strength of noncovalent interaction in several families of heterocycles. ${ }^{3}$ The main geometrical parameters and the corresponding interaction energies are shown in Table 2. For $\mathrm{N}_{2}$, the $\mathrm{N} \cdots \mathrm{C}=\mathrm{O}$ interaction is the strongest one in all cases with the exception of R = -SCN, in which the $\mathrm{N} \cdots \mathrm{Cl}(3.036 \AA)$ contact is slightly shorter than the $\mathrm{N} \cdots \mathrm{C}(3.126 \AA)$ one due to the interaction of the donor oxygen with the electrophilic region of the chlorine atom. It must be noted that the interaction energies are, in general, smaller than in the previous case, in line with the lower donating capability of $\mathrm{N}$ with respect to 0 . The $V_{\mathrm{s} \text {, min }}$ values for $\mathrm{CF}_{3}-\mathrm{COCl}$ and $\mathrm{N}_{2}$ are -18 and $-9 \mathrm{kcal} / \mathrm{mol}$, 
respectively. Also any possibility of dipole-dipole interaction is diminished with the use of $\mathrm{N}_{2}$.

Table 2. Key geometrical parameters and interaction energies for the optimized $\mathrm{N}_{2} \cdots \mathrm{R}-\mathrm{COF}\left(\mathrm{R}=\mathrm{R}=-\mathrm{CH}_{3},-\mathrm{OCH}_{3},-\mathrm{OCF}_{3},-\mathrm{SCN},-\mathrm{NH}_{2},-\mathrm{C}_{6} \mathrm{H}_{5},-\mathrm{C}_{6} \mathrm{H}_{5} \mathrm{~F},-\mathrm{C}_{6} \mathrm{H}_{2} \mathrm{~F}_{3}\right)$ adducts.

\begin{tabular}{llll}
\hline $\mathrm{R}$ & $\mathrm{D}_{\mathrm{N} \cdots \mathrm{C}}(\AA)$ & $\alpha\left(^{\circ}\right)$ & $\Delta \mathrm{E}_{\text {int }}(\mathrm{kcal} / \mathrm{mol})$ \\
\hline$-\mathrm{CH}_{3}$ & 3.043 & 92.42 & -1.08 \\
$-\mathrm{OCH}_{3}$ & 2.972 & 93.14 & -1.16 \\
$-\mathrm{OCF}_{3}$ & 2.943 & 95.87 & -1.46 \\
$-\mathrm{SCN}$ & 3.126 & 109.75 & -1.42 \\
$-\mathrm{NH}_{2}$ & 3.038 & 88.42 & -0.94 \\
$-\mathrm{C}_{6} \mathrm{H}_{5}$ & 3.056 & 95.33 & -0.84 \\
$-\mathrm{C}_{6} \mathrm{H}_{4} \mathrm{~F}$ & 3.056 & 93.73 & -0.86 \\
$-\mathrm{C}_{6} \mathrm{H}_{2} \mathrm{~F}_{3}$ & 3.046 & 95.65 & -0.98 \\
$\mathrm{C}_{6} \mathrm{~F}_{5}$ & 3.016 & 97.46 & -1.42 \\
\hline
\end{tabular}

\section{$\underline{\text { MEP values as predictors }}$}

We wonder about the possibility of making predictions about the strength of an interaction or the associated intermolecular distance based on molecular properties that are known a priori. It has been claimed that the value of the MEP at the electrophilic centre $\left(\mathrm{V}_{\mathrm{s}, \max }\right)$ can be used to predict the strength of halogen bonds. $^{28,29}$ Recently, Wheeler et al. have developed a model to predict the stacking interaction in biologically active molecules using heterocycle descriptors derived from the electrostatic potential and electric field of the molecules involved. ${ }^{30}$ 
In the present case, the use of MEP values does not allow a general prediction but seems to work well for groups with the same donor species. Reasonably good linear dependences have been found between the $V_{\mathrm{s} \text {, max }}$ value at the electron-deficient acceptor and the interaction energy for the same electronrich donor (Figure 7). This fact indicates that the electrostatic interaction is not the only significant contribution to the intermolecular attraction. Moreover, in the case of an oxygen donor (red squares in Figure 7), the more pronounced slope is associated with shorter $0 \cdots \mathrm{C}$ contacts that should involve enhanced orbital overlap and, thus, a larger charge transfer component. We have seen above that for these short contacts the energy difference is dictated by the $0 \cdot \cdot \mathrm{C}=0$ attack angle, which is characteristic of an orbital interaction. ${ }^{13}$

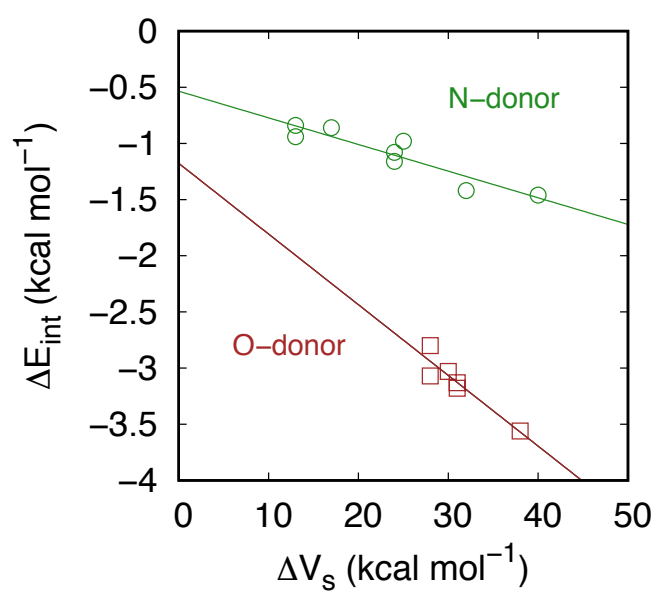

Figure 7. Relationship between the donor-acceptor MEP difference $\left(\Delta V_{s}\right)$ and the interaction energy $\left(\Delta \mathrm{E}_{\text {int }}\right)$ for the adducts studied in this work. Green circles $\left(\mathrm{R}^{2}=\right.$ $0.856)$ and red squares $\left(R^{2}=0.869\right)$ represent donors with nitrogen and oxygen atoms, respectively.

\section{Energy decomposition analysis}

In the light of the above results and to try to understand the nature of lone pair...carbonyl interactions in acyl halides at different contact distances, we have performed an energy decomposition analysis (EDA) on several different dimers, with oxygen as the lone pair donor, directly retrieved from experimental structures and one computational adduct, $\left(\mathrm{F}_{3} \mathrm{C}-\mathrm{COCl} \cdots \mathrm{CF}_{3}-\mathrm{COF}\right)$. The results are summarized in Table 3. 
Table 3. Energy decomposition analysis for selected systems with $0 \cdots \mathrm{C}=0$ short contacts. All energies are given in $\mathrm{kcal} / \mathrm{mol}$.

\begin{tabular}{|c|c|c|c|c|c|c|c|}
\hline Adduct & $\begin{array}{l}\text { Norm. } \\
\mathrm{d}_{Y \ldots \mathrm{C}}(\AA)\end{array}$ & $\Delta \mathrm{E}_{\text {Pauli }}$ & $\Delta \mathrm{E}_{\text {ELEC }}$ & $\Delta \mathrm{E}_{\text {DISP }}$ & $\Delta \mathrm{E}_{\mathrm{POL}}$ & $\Delta \mathrm{E}_{\mathrm{CT}}$ & $\Delta \mathrm{E}_{\mathrm{INT}}$ \\
\hline $\begin{array}{l}\mathrm{F}_{3} \mathrm{C}-\mathrm{COCl} \cdots \\
\mathrm{CF}_{3}-\mathrm{COF}\end{array}$ & -0.516 & 12.338 & -10.481 & -3.941 & -0.596 & -0.504 & -3.183 \\
\hline ABAZUY31 & -0.320 & 7.085 & -5.698 & -2.638 & -0.335 & -0.318 & -1.904 \\
\hline AZOYAP 32 & -0.256 & 5.842 & -5.712 & -2.304 & -0.343 & -0.099 & -2.617 \\
\hline BAPLUZ $^{33}$ & -0.190 & 7.432 & -5.627 & -3.219 & -0.343 & -0.298 & -2.054 \\
\hline BEWTIH $^{34}$ & -0.293 & 5.728 & -5.545 & -2.242 & -0.291 & -0.188 & -2.538 \\
\hline CECBAO $^{35}$ & -0.384 & 6.502 & -6.119 & -2.606 & -0.363 & -0.184 & -2.771 \\
\hline FAYNOI $^{36}$ & -0.680 & 22.344 & -21.436 & -5.526 & -2.055 & -2.121 & -8.794 \\
\hline ISADIP $^{26}$ & -0.357 & 7.513 & -6.585 & -2.888 & -0.318 & -0.131 & -2.410 \\
\hline ISADOV $^{26}$ & -0.315 & 7.623 & -6.664 & -2.897 & -0.391 & -0.301 & -2.631 \\
\hline LEZZOI $^{37}$ & -0.341 & 7.284 & -7.665 & -2.664 & -0.518 & -0.216 & -3.780 \\
\hline WEWGIP38 & -0.179 & 6.457 & -5.109 & -3.131 & -0.402 & -0.301 & -2.485 \\
\hline XANLUU39 & -0.354 & 9.842 & -7.746 & -3.856 & -0.523 & -0.467 & -2.750 \\
\hline XANMEF39 & -0.093 & 4.502 & -2.850 & -2.191 & -0.403 & -0.186 & -1.129 \\
\hline YAYHIR 40 & -0.053 & 7.111 & -5.642 & -3.643 & -0.497 & -0.373 & -3.046 \\
\hline
\end{tabular}

In general, the interaction energy increases when shortening the $0 \cdots \mathrm{C}$ distance. It is worth noting that dispersion contributes in a great extent to the total attractive forces and polarization and charge transfer terms are also present in all cases. We have used the M06-2X functional because of its high 
parameterization with non-covalently bonded systems, and we have checked that adding the D3 dispersion correction (M06-2X-D3) only increases the dispersion component ( $\Delta \mathrm{E}_{\text {DISP }}$ ) by a $5-6 \%$.

The two components associated with orbital interactions, polarization and charge transfer, tend to be more important for shorter interaction distances. For instance, for FAYNOI, with a very short $0 \cdots$ C distance $(0.680 \AA$ shorter than the sum of the corresponding van der Waals radii), $\Delta \mathrm{E}_{\text {Ст }}$ accounts for -2.121 $\mathrm{kcal} / \mathrm{mol}$, which is the $24 \%$ of the total interaction energy. On the other hand, for dimers with longer intermolecular distances, the orbital contribution is considerably smaller (e.g. 12\% in WEWGIP, or 14.5\% in BAPLUZ).

Interestingly, Pauli repulsion energy ( $\left.\Delta \mathrm{E}_{\text {Pauli }}\right)$ is very large and is greatly compensated by an electrostatic attractive component $\left(\Delta \mathrm{E}_{\mathrm{ELEC}}\right)$. However, the sum of $\Delta \mathrm{E}_{\text {Pauli }}$ and $\Delta \mathrm{E}_{\mathrm{ELEC}}$ is positive in all case except in LEZZOI. This is the only structure in which the group attached to the CO-X moiety is $-\mathrm{NR}_{2}$, involving MEP values at the 0 -donor and $\mathrm{C}$-acceptor of -27 and $+47 \mathrm{kcal} / \mathrm{mol}$, respectively, which could explain the enhanced electrostatic attraction and a large interaction energy of $-3.780 \mathrm{kcal} / \mathrm{mol}$. In any case, the significant electrostatic nature of the interaction is reflected by the fact that $\Delta \mathrm{E}_{\mathrm{ELEC}}$ is the largest term among all negative (attractive terms) energies.

\section{Conclusions}

We have carried out a comprehensive analysis, both structural and theoretical, of lone pair-carbonyl interactions in acyl halides (R-CO-X). The structural analysis of the CSD has shown that these contacts follow precise geometrical arrangements, with attack angles approaching $100^{\circ}$ as the lone paircarbonyl distance shortens. A MEP analysis has disclosed well-defined $\pi$-holes on the carbon atom of the carbonyl groups for all studied acyl halides. We have demonstrated that the value of the electrostatic potential at the $\pi$-hole increases when descending the periodic group for $\mathrm{X}=\mathrm{F}-\mathrm{I}$, also showing a high sensitivity to the nature of the R substituent.

The strength of the interaction depends on the nature of both the donor and the acceptor. Three main factors affect the interaction energy: 
a) The nature of $\mathrm{X}$ : we have observed stronger interactions for $\mathrm{X}=$ $\mathrm{F}$, which is in good agreement with our MEP analysis; however, the total interaction energy for $\mathrm{X}=\mathrm{F}$ - I correlates very well with the $\mathrm{Y} \cdots \mathrm{C}=\mathrm{O}$ angle, which reinforces the idea of a nonnegligible orbital nature of the interaction.

b) The effect of $\mathrm{R}$ is key since modulates the electrostatic potential distribution over the molecule and determines whether or not a $\pi$-hole interaction is established.

c) The nature of the lone pair: better donors, as oxygen, lead to stronger interactions.

We have also seen that the values of the MEP at the $\pi$-hole can be a good predictor of the interaction strength when the same donor atom is used. Furthermore, an EDA analysis has shown that the interaction is mainly electrostatic with an important dispersion contribution, and with a significant orbital (charge transfer) component for short distances that allow an optimum orbital overlap. Finally, the computed interaction energies, in the range 1-8 $\mathrm{kcal} / \mathrm{mol}$ for a single lone pair-carbonyl contact, allow the use of these interactions in crystal design and supramolecular chemistry.

\section{Theoretical methods}

Structural searches were done in the Cambridge Structural Database $(C S D)^{20}$ version 5.40, November 2018. Only crystal structures with 3D coordinates determined, non-disordered, with no errors, not polymeric and with $\mathrm{R}<0.05$ were allowed in searches. CSD refcodes of selected examples are given throughout the text as six-letter codes (e.g., ABCDEF). We used the van der Waals radii proposed by Alvarez. ${ }^{41}$ Electronic structure calculations were performed at the DFT level with the highly parameterized M06-2X functional and def2-TZVP basis set. Interaction energies were corrected for the BSSE by means of the Counterpoise method. ${ }^{42}$ All optimized structures were confirmed to be real minima of the corresponding potential energy surfaces by frequencies analyses. MEP maps were built on the $0.002 \AA$ isosurface with GaussView ${ }^{43}$ on the molecular geometries of the interacting systems. Natural bond orbitals (NBO) 
analyses were done at the same DFT level with the NB03.1 software $^{44}$ as implemented in Gaussian16. EDA analyses were carried out with Q-Chem 5.045 by means of the second generation ALMO-EDA method. ${ }^{46}$ All other quantum chemistry calculations were done with Gaussian $16 .{ }^{47}$

\section{Acknowledgements}

Financial support from MINECO PGC2018-093863-B-C21, the Spanish Structures of Excellence María de Maeztu program throough grant MDM-20170767, and AGAUR through grant 2017-SGR-1289 is gratefully acknowledged. J.E. thanks the Spanish MICINN for a Ramón y Cajal research contract (RYC-201722853). J.D.V. acknowledges the Universitat de Barcelona for a predoctoral APIF grant.

\section{References}

(1) Echeverría, J., Intermolecular Carbonyl...Carbonyl Interactions in TransitionMetal Complexes. Inorg. Chem. 2018, 57, 5429-5437.

(2) Echeverría, J., The $n \rightarrow \pi^{*}$ interaction in metal complexes. Chem. Commun. 2018, 54, 3061-3064.

(3) Echeverría, J., Noncovalent Interactions in Succinic and Maleic Anhydride Derivatives. Cryst. Growth Des. 2018, 18, 506-512.

(4) Newberry, R. W.; VanVeller, B.; Guzei, I. A.; Raines, R. T., $n \rightarrow \pi^{*}$ Interactions of Amides and Thioamides: Implications for Protein Stability. J. Am. Chem. Soc. 2013, 135, 7843-7846.

(5) Newberry, R. W.; Raines, R. T., A Key $n \rightarrow \pi^{*}$ Interaction in N-Acyl Homoserine Lactones. ACS Chem. Biol. 2014, 9, 880-883.

(6) Bretscher, L. E.; Jenkins, C. L.; Taylor, K. M.; DeRider, M. L.; Raines, R. T., Conformational stability of collagen relies on a stereoelectronic effect. J. Am. Chem. Soc. 2001, 123, 777-778.

(7) Singh, S. K.; Das, A., The $n \rightarrow \pi^{*}$ interaction: a rapidly emerging non-covalent interaction. Phys. Chem. Chem. Phys. 2015, 17, 9596-9612.

(8) Singh, S. K.; Mishra, K. K.; Sharma, N.; Das, A., Direct Spectroscopic Evidence for an $\mathrm{n} \rightarrow \pi^{*}$ Interaction. Angew. Chem. Int. Ed. 2016, 55, 7801-7805.

(9) Perras, F. A.; Marion, D.; Boisbouvier, J.; Bryce, D. L.; Plevin, M. J., Observation of $\mathrm{CH} \cdots \pi$ Interactions between Methyl and Carbonyl Groups in Proteins. Angew. Chem. Int. Ed. 2017, 56, 7564-7567.

(10) Doppert, M. T.; van Overeem, H.; Mooibroek, T. J., Intermolecular $\pi$-hole $/ n \rightarrow \pi^{*}$ interactions with carbon monoxide ligands in crystal structures. Chem. Commun. 2018, 54, 12049-12052.

(11) Bauzá, A.; Frontera, A., Theoretical study on $\sigma$ - and $\pi$-hole carbon $\cdots$ ]carbon bonding interactions: implications in CFC chemistry. Phys. Chem. Chem. Phys. 2016, 18, 32155-32159.

(12) Del Bene, J. E.; Alkorta, I.; Elguero, J., Pnicogen bonds in complexes with CO and CS: differentiating properties. Mol. Phys. 2019, 117, 1117-1127.

(13) Kamer, K. J.; Choudhary, A.; Raines, R. T., Intimate Interactions with Carbonyl Groups: Dipole-Dipole or $n \rightarrow \pi^{*}$ ? J. Org. Chem. 2013, 78, 2099-2103. 
(14) Sahariah, B.; Sarma, B. K., Relative orientation of the carbonyl groups determines the nature of orbital interactions in carbonyl-carbonyl short contacts. Chem. Sci. 2019, 10, 909-917.

(15) Newberry, R. W.; Raines, R. T., The $\mathrm{n} \rightarrow \pi^{*}$ Interaction. Acc. Chem. Res. 2017, 50, 1838-1846.

(16) Bauzá, A.; Mooibroek, T. J.; Frontera, A., The Bright Future of Unconventional $\sigma / \pi$-Hole Interactions. ChemPhysChem 2015, 16, 2496-2517.

(17) Wang, H.; Wang, W.; Jin, W. J., $\sigma$-Hole Bond vs $\pi$-Hole Bond: A Comparison Based on Halogen Bond. Chem. Rev. 2016, 116, 5072-5104.

(18) Murray, J. S.; Lane, P.; Clark, T.; Riley, K. E.; Politzer, P., $\sigma$-Holes, $\pi$-holes and electrostatically-driven interactions. J. Mol. Model. 2012, 18, 541-548.

(19) Zhao, L. L.; von Hopffgarten, M.; Andrada, D. M.; Frenking, G., Energy decomposition analysis. WIREs-Comput.l Mol. Sci. 2018, 8.

(20) Groom, C. R.; Bruno, I. J.; Lightfoot, M. P.; Ward, S. C., The Cambridge Structural Database. Acta Crystallogr. Sect. B 2016, 72, 171-179.

(21) Burgi, H. B.; Dunitz, J. D.; Shefter, E., Geometrical reaction coordinates. II. Nucleophilic addition to a carbonyl group. J. Am. Chem. Soc. 1973, 95, 5065-5067.

(22) Burgi, H. B.; Dunitz, J. D.; Lehn, J. M.; Wipff, G., Stereochemistry of reaction paths at carbonyl centres. Tetrahedron 1974, 30, 1563-1572.

(23) Mayer, F.; Oberhammer, H.; Berkei, M.; Pernice, H.; Willner, H.; Bierbrauer, K.; Paci, M. B.; Argüello, G. A., Structural and Conformational Properties of Fluoroformic Acid Anhydride, FC(O)OC(O)F. Inorg. Chem. 2004, 43, 8162-8168.

(24) Berrueta Martínez, Y.; Reuter, C. G.; Vishnevskiy, Y. V.; Bava, Y. B.; Picone, A. L.; Romano, R. M.; Stammler, H.-G.; Neumann, B.; Mitzel, N. W.; Della Védova, C. O., Structural Analysis of Perfluoropropanoyl Fluoride in the Gas, Liquid, and Solid Phases. J. Phys. Chem. A 2016, 120, 2420-2430.

(25) Sjoberg, P.; Politzer, P., Use of the electrostatic potential at the molecular surface to interpret and predict nucleophilic processes. J. Phys. Chem. 1990, 94, 3959-3961.

(26) Erben, M. F.; Della Védova, C. O.; Boese, R.; Willner, H.; Oberhammer, H., Trifluoromethyl Chloroformate, $\mathrm{ClC}(\mathrm{O}) \mathrm{OCF}_{3}$ : Structure, Conformation, and Vibrational Analysis Studied by Experimental and Theoretical Methods. J. Phys. Chem. A 2004, 108, 699-706.

(27) Rahim, A.; Saha, P.; Jha, K. K.; Sukumar, N.; Sarma, B. K., Reciprocal carbonylcarbonyl interactions in small molecules and proteins. Nature Commun. 2017, 8, 78.

(28) Perera, M. D.; Desper, J.; Sinha, A. S.; Aakeröy, C. B., Impact and importance of electrostatic potential calculations for predicting structural patterns of hydrogen and halogen bonding. CrystEngComm 2016, 18, 8631-8636.

(29) Corpinot, M. K.; Bučar, D.-K., A Practical Guide to the Design of Molecular Crystals. Cryst. Growth Des. 2019, 19, 1426-1453.

(30) Bootsma, A. N.; Doney, A. C.; Wheeler, S. E., Predicting the Strength of Stacking Interactions between Heterocycles and Aromatic Amino Acid Side Chains. J. Am. Chem. Soc. 2019.

(31) Romano, R. M.; Della Védova, C. O.; Boese, R., N-sulfinylimine fluorocarbonylsulphane, FC(O)SNSO: solid structure and theoretical calculations. J. Mol. Struct. 1999, 513, 79-84.

(32) Della Védova, C. O.; Downs, A. J.; Novikov, V. P.; Oberhammer, H.; Parsons, S.; Romano, R. M.; Zawadski, A., Fluorocarbonyl Trifluoromethanesulfonate, FC(0)OSO2CF3: Structure and Conformational Properties in the Gaseous and Condensed Phases. Inorg. Chem. 2004, 43, 4064-4071.

(33) M. Romano, R.; O. Della Védova, C.; Boese, R.; Hildebrandt, P., Structural and spectroscopic characterization of $\mathrm{ClC}(0)$ SNSO. A theoretical and experimental study. Phys. Chem. Chem. Phys. 1999, 1, 2551-2557. 
(34) Pernice, H.; Berkei, M.; Henkel, G.; Willner, H.; Argüello, G. A.; McKee, M. L.; Webb, T. R., Bis(fluoroformyl)trioxide, FC(0)000C(0)F. Angew. Chem. Int. Ed. 2004, 43, 2843 2846.

(35) Boese, R.; Cutin, E. H.; Mews, R.; Robles, N. L.; Della Védova, C. O., ((Fluoroformyl)imido)sulfuryl Difluoride, FC(O)NS(O)F2: Structural, Conformational, and Configurational Properties in the Gaseous and Condensed Phases. Inorg. Chem. 2005, 44, 9660-9666.

(36) Moeller, G.; Olmstead, M. M.; Tinti, D. S., Structure and spectra of the 1:1 addition compound of 1,4-dioxane and oxalyl fluoride. J. Am. Chem. Soc. 1987, 109, 95-98.

(37) Leitz, D.; Stierstorfer, K.; Kornath, A., Crystal Structure and Vibrational Spectra of ClSO2NHC(O)F. Z. Anorg. Allg. Chem. 2018, 644, 411-414.

(38) Erben, M. F.; Della Védova, C. O.; Willner, H.; Boese, R., Synthesis, Structure and Conformational Properties of Fluoroformylchlorodifluoroacetyl Disulfide, $\mathrm{FC}(\mathrm{O}) \mathrm{SSC}(\mathrm{O}) \mathrm{CF}_{2} \mathrm{Cl}$ : Conformational Transferability in -C(O)SSC(0)-Compounds. Eur. J. Inorg. Chem. 2006, 2006, 4418-4425.

(39) Grossel, M. C.; Hursthouse, M. B.; Orton, J. B., Structural investigation of x,y-bis(chlorocarbonyl) pyridines derivatives: "strength in diversity" - a disparity of supramolecular packing motifs. CrystEngComm 2005, 7, 279-283.

(40) Fan, X.; Wang, Y.; Jin, C.; Jin, L., Benzene-1,3,5-tricarbonyl trichloride. Acta Crystallogr. Sect. E 2012, 68, o1260.

(41) Alvarez, S., A cartography of the van der Waals territories. Dalton Trans. 2013, 42, 8617-8636.

(42) Boys, S. F.; Bernardi, F., The calculation of small molecular interactions by the differences of separate total energies. Some procedures with reduced errors. Mol. Phys. 1970, 19, 553-566.

(43) GaussView, version 5, R. Dennington, T. Keith and J. Millam, Semichem Inc., Shawnee Mission, KS, 2009.

(44) NBO Version 3.1, E. D. Glendening, A. E. Reed, J. E. Carpenter, and F. Weinhold.

(45) Shao, Y.; Gan, Z.; Epifanovsky, E.; Gilbert, A. T. B.; Wormit, M.; Kussmann, J.; Lange, A. W.; Behn, A.; Deng, J.; Feng, X.; Ghosh, D.; Goldey, M.; Horn, P. R.; Jacobson, L. D.; Kaliman, I.; Khaliullin, R. Z.; Kuś, T.; Landau, A.; Liu, J.; Proynov, E. I.; Rhee, Y. M.; Richard, R. M.; Rohrdanz, M. A.; Steele, R. P.; Sundstrom, E. J.; Woodcock, H. L.; Zimmerman, P. M.; Zuev, D.; Albrecht, B.; Alguire, E.; Austin, B.; Beran, G. J. O.; Bernard, Y. A.; Berquist, E.; Brandhorst, K.; Bravaya, K. B.; Brown, S. T.; Casanova, D.; Chang, C.-M.; Chen, Y.; Chien, S. H.; Closser, K. D.; Crittenden, D. L.; Diedenhofen, M.; DiStasio, R. A.; Do, H.; Dutoi, A. D.; Edgar, R. G.; Fatehi, S.; Fusti-Molnar, L.; Ghysels, A.; Golubeva-Zadorozhnaya, A.; Gomes, J.; Hanson-Heine, M. W. D.; Harbach, P. H. P.; Hauser, A. W.; Hohenstein, E. G.; Holden, Z. C.; Jagau, T.-C.; Ji, H.; Kaduk, B.; Khistyaev, K.; Kim, J.; Kim, J.; King, R. A.; Klunzinger, P.; Kosenkov, D.; Kowalczyk, T.; Krauter, C. M.; Lao, K. U.; Laurent, A. D.; Lawler, K. V.; Levchenko, S. V.; Lin, C. Y.; Liu, F.; Livshits, E.; Lochan, R. C.; Luenser, A.; Manohar, P.; Manzer, S. F.; Mao, S.-P.; Mardirossian, N.; Marenich, A. V.; Maurer, S. A.; Mayhall, N. J.; Neuscamman, E.; Oana, C. M.; Olivares-Amaya, R.; O’Neill, D. P.; Parkhill, J. A.; Perrine, T. M.; Peverati, R.; Prociuk, A.; Rehn, D. R.; Rosta, E.; Russ, N. J.; Sharada, S. M.; Sharma, S.; Small, D. W.; Sodt, A.; Stein, T.; Stück, D.; Su, Y.-C.; Thom, A. J. W.; Tsuchimochi, T.; Vanovschi, V.; Vogt, L.; Vydrov, O.; Wang, T.; Watson, M. A.; Wenzel, J.; White, A.; Williams, C. F.; Yang, J.; Yeganeh, S.; Yost, S. R.; You, Z.-Q.; Zhang, I. Y.; Zhang, X.; Zhao, Y.; Brooks, B. R.; Chan, G. K. L.; Chipman, D. M.; Cramer, C. J.; Goddard, W. A.; Gordon, M. S.; Hehre, W. J.; Klamt, A.; Schaefer, H. F.; Schmidt, M. W.; Sherrill, C. D.; Truhlar, D. G.; Warshel, A.; Xu, X.; Aspuru-Guzik, A.; Baer, R.; Bell, A. T.; Besley, N. A.; Chai, J.-D.; Dreuw, A.; Dunietz, B. D.; Furlani, T. R.; Gwaltney, S. R.; Hsu, C.-P.; Jung, Y.; Kong, J.; Lambrecht, D. S.; Liang, W.; Ochsenfeld, C.; Rassolov, V. A.; Slipchenko, L. V.; Subotnik, J. E.; Van Voorhis, T.; Herbert, J. M.; Krylov, A. I.; Gill, P. M. W.; Head-Gordon, M., Advances in molecular quantum chemistry contained in the Q-Chem 4 program package. Mol. Phys. 2015, 113, 184-215. 
(46) Horn, P. R.; Mao, Y.; Head-Gordon, M., Probing non-covalent interactions with a second generation energy decomposition analysis using absolutely localized molecular orbitals. Phys. Chem. Chem. Phys. 2016, 18, 23067-23079.

(47) Gaussian 16, Revision B.01, Frisch, M. J.; Trucks, G. W.; Schlegel, H. B.; Scuseria, G. E.; Robb, M. A.; Cheeseman, J. R.; Scalmani, G.; Barone, V.; Petersson, G. A.; Nakatsuji, H.; Li, X.; Caricato, M.; Marenich, A. V.; Bloino, J.; Janesko, B. G.; Gomperts, R.; Mennucci, B.; Hratchian, H. P.; Ortiz, J. V.; Izmaylov, A. F.; Sonnenberg, J. L.; Williams-Young, D.; Ding, F.; Lipparini, F.; Egidi, F.; Goings, J.; Peng, B.; Petrone, A.; Henderson, T.; Ranasinghe, D.; Zakrzewski, V. G.; Gao, J.; Rega, N.; Zheng, G.; Liang, W.; Hada, M.; Ehara, M.; Toyota, K.; Fukuda, R.; Hasegawa, J.; Ishida, M.; Nakajima, T.; Honda, Y.; Kitao, O.; Nakai, H.; Vreven, T.; Throssell, K.; Montgomery, J. A., Jr.; Peralta, J. E.; Ogliaro, F.; Bearpark, M. J.; Heyd, J. J.; Brothers, E. N.; Kudin, K. N.; Staroverov, V. N.; Keith, T. A.; Kobayashi, R.; Normand, J.; Raghavachari, K.; Rendell, A. P.; Burant, J. C.; Iyengar, S. S.; Tomasi, J.; Cossi, M.; Millam, J. M.; Klene, M.; Adamo, C.; Cammi, R.; Ochterski, J. W.; Martin, R. L.; Morokuma, K.; Farkas, O.; Foresman, J. B.; Fox, D. J. Gaussian, Inc., Wallingford CT, 2016. 


\section{FOR TABLE OF CONTETS ONLY}

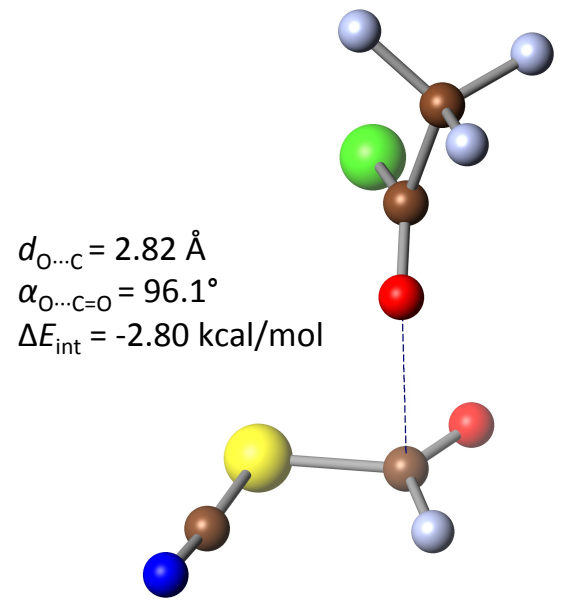

Lone pair..carbonyl interactions are present in the crystal structures of acyl halides. Such contacts are highly directional and their strength can be modulated by modification of the substituents. 